\section{Thirty years of transgenic plants}

This month marks the 30th anniversary of the first successful introduction of a foreign gene into a plant (L. Herrera-Estrella et al. Nature 303, 209-213; 1983). To overcome today's huge agricultural hurdles, we should move to a model that combines the best features of transgenic technology with those of organic and conventional farming.

Genetic engineering has revolutionized fundamental plant research and accelerated strategic improvements in crops. More than 170 million hectares of genetically modified crops were grown worldwide last year, to the benefit of the environment and society (see nature.com/gmcrops).

These achievements are founded on pioneering studies from 1947, when plant pathologist Armin Braun suggested that DNA from Agrobacterium tumefaciens, a bacterium that infects plants, could induce plant tumours. Subsequent work (1974-80) by the groups of Marc Van Montagu and Jeff Schell in Belgium, Mary-Dell Chilton in the United States and Rob Schilperoort in the Netherlands revealed that A. tumefaciens delivers a segment of its DNA into the plant's nuclear DNA using a plasmid-integration system - one of the earliest discoveries of a natural DNAtransfer mechanism. In May 1983, the Van Montagu and Schell lab deployed this system as a geneexpression vector, and the first transgenic plants became fact. Wim Grunewald, Jo Bury Flanders Institute for Biotechnology (VIB), Ghent, Belgium. wim.grunewald@vib.be Dirk Inzé VIB; and Ghent University, Ghent, Belgium.

\section{The high cost of overspecialization}

In their entreaty to bring "all available data" back into the fold of phylogenetic systematics,
Quentin Wheeler and colleagues attribute the epidemic of DNA sequence analyses to certain key advantages of DNA data (Nature 496, 295-296, 2013). We suggest another, more basic explanation.

After years of training in understanding taxonomic groups and evaluating complex characters, scientists can find themselves overspecialized in a particular taxon, making them uncompetitive for employment and funding opportunities. Analysing DNA sequence data, which relies less on specialized taxonomic knowledge, does not exact such a high cost.

Xiaolei Huang, Gexia Qiao Institute of Zoology, Chinese Academy of Sciences, Beijing, China. huangxl@ioz.ac.cn

Colin Favret University of Montreal, Canada.

\section{Journals should be clear on misconduct}

The next World Conference on Research Integrity in Montreal, Canada, on 5-8 May will make collaborators more responsible for the integrity of their research (see go.nature.com/lsd1p5). I believe that more pressure should also be brought to bear on scientific journals, which should publicly declare and reinforce their policies on fraudulent reporting of research results.

Journals were urged in 2010 to improve procedures for tackling allegations of misconduct and irresponsible research practices (www.singaporestatement. org). But progress has been unsatisfactory: some $40 \%$ of highimpact biomedical journals, for example, do not have authorship policies, let alone policies to define, prevent and punish misconduct (X. Bosch et al. PLoS ONE 7, e51928; 2012).

There is little excuse for this failure to act against a common, long-standing problem. Editorial associations and publishers have established guidelines on editors' responsibilities regarding suspected or confirmed misconduct in papers (see go.nature.com/egc43n). Automatic detection of plagiarism and image manipulation is now widespread, and compulsory disclosure of financial and nonfinancial conflicts of interest is becoming standard practice.

Legal disputes and other complications can embroil journals that do not publicly state their policies on misconduct. Worse, those journals serve the scientific community badly. Xavier Bosch Department of Internal Medicine, Hospital Clinic, University of Barcelona, Spain. xavbosch@clinic.ub.es

\section{Don't judge research on economics alone}

Colin Macilwain argues that scientific research and development in the West should be contributing more to economic prosperity (Nature 495, $143 ; 2013)$. I disagree that this is a problem in the United States.

A 2007 report from the US National Academies indicated that advances in science and technology would benefit the US economy and underpin its competitiveness in the global job market (see go.nature.com/ qnir4w). Despite the effects of the global financial crisis, this outlook holds largely true.

For example, a move by ten midwestern US states towards green energy will create 85,700 jobs, produce US $\$ 41$ billion in new investment and cut utility bills by $\$ 43$ billion, while reducing annual carbon emissions by an amount equivalent to that from 30 coal-powered plants (see go.nature.com/e5if8v).

Research should not be judged solely by its economic benefits. Biomedical scientists, for instance, do not generally search for disease cures to get rich. It is also difficult to place monetary value on the doubling of US life expectancy from 1850 to 2008 mainly owing to medical research and to improvements in water and sewage treatments.
Many other big problems faced by humankind, including transportation, finite natural resources, overpopulation, environmental degradation and climate change, can be solved only by science and technology, irrespective of profit motives. Thomas E. DeCoursey Rush University Medical Center, Chicago, Illinois, USA. tdecours@rush.edu

\section{Open-access boom in developing nations}

Open-access publication is not always about making publicly funded research articles freely available (Nature 495, 425; 2013). Other factors could be driving the boom in open-access publishing in scientifically emerging nations.

The Directory of Open Access Journals (go.nature. com/nsrmrb) shows that the United Kingdom has 587 openaccess journals, Spain has 465, Germany has 286 and France, 185. Brazil publishes 843 - the second-highest number after the United States $(1,312)$. India is fourth (518) and Egypt is sixth (363). Romania publishes more open-access journals than Italy (264 and 256, respectively), and Turkey, Colombia and Iran each publish more than France.

Few open-access journals from the developing world are internationally recognized, however, or listed in scientific databases such as PubMed. This omission excludes the journals from impact calculations and limits the pool of international peer-reviewers, undermining the rigour of articles and their value to the public.

Despite this, the proliferation of publications in such local open-access journals can promote researchers' careers in countries in which academic evaluation depends mainly on the number, not quality, of publications. Jagadeesh Bayry Institut National de la Santé et de la Recherche Médicale, Paris, France. jagadeesh.bayry@crc.jussieu.fr 